sion. In spite of prolonged complaints over the years, defence lawyers have not been able to obtain recognition from the military courts that their clients have been tortured and sometimes killed by their interrogators, while members of Shabak have often been acquitted of violations. There is a valuable description of the role of the autopsy in cases of death in custody in different countries around the world, whether by the "black box" method, under which the pathologist has access only to the physical evidence displayed by the body, or the "gestalt" method, whereby the pathologist has all relevant material before him or her and has an opportunity to determine the circumstances as well as the immediate cause of death. In Israel, the former method is in use, so that the autopsy is isolated from the scene and circumstantial aspects of the case, thus allowing courts to ignore or refute damaging evidence.

It is an astonishing fact that the GSS, which is able to request the police to arrest a suspect and then take him for prolonged interrogation and which has independent interrogation wings in prisons, and whose sealed evidence can persuade a judge to extend a prisoner's detention, has no status in law. Indeed its very existence was denied until the Landau Commission gave it legitimacy in 1985. Before that time Israel was a "denying" state. Now it is an "inquisition" state.

The final section of the book deals with the rehabilitation of torture victims: firstly identification and recognition is covered, then comes a survey of the experience of Palestinians in Israeli prisons; the role of compensation in rehabilitation follows, and finally, there is a description of the founding and ethos of the Medical Foundation for the Care of Victims of Torture in London.

Useful appendices list the international declarations against torture and for the protection of prisoners, as well as codes of medical and nursing ethics.

This is a very disturbing book which presents its evidence persuasively. Since it was published, events have moved forward - the Occupied Territories are being returned to Palestinian rule so there should be fewer detainees subject to interrogation and torture, but a new "Prohibition of Torture" Bill, at present before the Israeli Knesset, appears designed to relax rather than strengthen controls on interrogation of detainees.

DUNCAN FORREST

Medical Foundation for the Care of Victims of Torture, 96-98 Grafton Street, London NW5 $3 E \mathcal{F}$

\section{The Ethics of Animal and Human Experimentation}

Edited by Peter P De Deyn, London, John Libbey and Co, 1994, 369 pages, £40, \$US74.

A good deal of experimentation in medicine is conducted upon animals and humans, and a good many ethical issues arise in the course of such research. The present volume discusses a number of these issues. The authors are mostly drawn from Belgium and the Netherlands and come from a number of different disciplines, though clinical and laboratory scientists predominate. I think Anglo-American medical ethicists will be interested to see the fruits of Belgian and Dutch thinking on many of the very topics that engage them. Certainly, no one could come away from this volume unimpressed by the collective attempt to show that ethically sensitive biomedical research of high quality is possible.

The book opens with sections on ethics and medicine and on legislation on animal/human experimentation in Belgium and the Netherlands. The latter section is quite interesting, and the papers by Nys and van Wijman give the reader at least an elementary working knowledge of the state of play in those two countries. The former section is rather disappointing: the papers provide no extended discussion of specific ethical frameworks within which questions about the justification of our research practices with animals and humans can be pursued; neither do they go into the important differences that characterise competing ethical frameworks - frameworks which many of us are often forced to choose between.

The book then proceeds with successive sections on animal research, on randomised clinical trials, and on medical research on humans of special interest, such as children, psychiatric patients, and those with AIDS. These three sections form the substance of the book, and the last section, particularly in light of the papers by Cosyns on psychiatric patients as research $\overline{\bar{\gamma}}$ subjects, Clara on research involving children, and Annas on research on patients with AIDS and cancer, is quite successful in bringing out how our ethical thinking has to take account of the special circumstances of different research subjects. The section on randomised clinical trials is too diffuse to come to a specific point, but the papers by Dillmann on $\overrightarrow{0}$ Alzheimer's disease, Kimsma on some of the tussles to do with informed con- $\omega$ sent, and Noach on ethics in drug development are quite interesting. As for the section to do with animal iv research, it rather predictably comes to the conclusion that our use of animals for medical purposes is justi- o fied, and, apart from a paper by 0 Morrison on animal rights movements in the United States, there is little by way of opposition put in the way of reaching this conclusion.

While the essays do succeed in raising all manner of issues of ethical $\overrightarrow{0}$ import with regard to research o animals and humans, the book strik me as flawed at a deeper level. The central problem is not that there insufficient discussion of ethica्al frameworks within which to locate ethical debates, though this is indeed a $\stackrel{\varnothing}{\unrhd}$ problem, but that so much ethically $\overrightarrow{\vec{B}}$ is taken for granted, based upon currently accepted medical research practice, that deep challenges to many of these assumptions go unexplored. The result is a volume with which readers feel comfortable and so $\overparen{D}$ reassured, morally: to be sure, there $\frac{0}{3}$ are ethical issues to which we need to be more sensitive than we presently 0 are, ethical issues that we need to work further and more carefully upon, 윽 but by and large high quality medical research can be done within established ethical guidelines.

Things are too easy. For example, $N$ one of the assumptions that underlies $N$ most of the essays in this book is that benefit to humans can justify all $\omega$ manner of things in medical research, without any clear statement of why weco should think this or how exactly $\frac{}{D}$ arguments from benefit are supposed $\stackrel{\infty}{?}$ to run. Thus, in the animal research $\square$ section, human benefit is assumed to $\bar{O}$ justify animal research. How and in $\overrightarrow{\mathbb{D}}$ virtue of what is it supposed to do $\frac{O}{\mathbb{D}}$ this? And if it can justify using animals $\varrho$ to certain ends, why can it not justify using unfortunate humans to the same ends? Why does informed consent 
arise as some ethical barrier in the human case? And even if it does arise, why can we not conduct medical research on humans who are brain dead, anencephalic infants, and the like, where there never will be anything resembling informed consent? If we are told that we must respect humans, what about them are we to respect? Take, for instance, a person fully in the grip of Alzheimer's disease or senile dementia: is it the human shell we are to respect? Why may we not test drugs upon these people? To reply that our religious or cultural tradition does not sanction it is no longer the stopper it once was, since all manner of actions that many regard as capable of justification, from abortion to euthanasia and physicianassisted suicide, now regularly challenge that tradition. In short, hard questions are being asked of many practices that heretofore have been widely regarded as ethically acceptable, and while it may be true that ethically sensitive biomedical research of high quality is possible within established practices, is it possible when many of the very normative principles that underlie those practices themselves come under attack? It is the examination and the defence or rejection of these principles and so the practices based upon them - I do not prejudge the outcome of this activity that seem both central to and imperative for an ethical discussion of animal and human experimentation today.

R G FREY

Bowling Green State University

\section{Reforming Health Care}

Edited by David Seedhouse, Chichester, UK, John Wiley, 1995 242 pages, $£ 16.95$.

In this book, the seventh in a collection written or edited by David Seedhouse, he sets out to explore modern health reforms in depth. His aim is to show that philosophical analysis is essential to cogent health reform. The book is formed from a collection of articles, written by a range of international authors. Most of the articles have already appeared in Health Care Analysis: Fournal of Health Philosophy and Policy, also edited by David Seedhouse.

The book is divided into three sections. The first section consists of comprehensive articles offering an informed view of various health care systems, reforms and associated debates in the USA, the UK, New Zealand, the Netherlands, South Africa and Lithuania. These chapters give a rich insight into the different systems and the rationale and problems surrounding them. They range from discussion of reasons why urgent reforms to the systems within the US are thought to be necessary, to descriptions of difficulties faced in post-socialist Lithuania, where the majority of the population find great difficulty in obtaining a decent minimum of health care. The vast difficulties facing development of a new health care plan in post-apartheid South Africa, where there is evidence of gross racial discrepancies in health care, are also discussed. A separate article on the oft-quoted Oregon experiment is also included in this first section This describes in detail the still evolving attempts by this American state to devise, in consultation with the community, a basic health care package which, by eliminating procedures which are judged to be least beneficial (for example treatment of viral hepatitis and cancers with less than five per cent predicted recovery at five years), can release funds to cover health care costs for the poorest in society, ie those who cannot afford health insurance.

The six chapters in the second section also refer to various health care systems but are devoted to philosophical discussion, with particular reference to social justice. The third section consists of an examination of the ethics of health promotion. The four authors of this section explore issues such as the nature of health, the extent to which individuals can be held responsible for their own health, and the related issue of "victim blaming". Working on the premise that a theory of health is essential if discussions of health policies are to have any real meaning, their aim is to illustrate the features which are essential to any theory of health.

This book is on the whole, clearly written and easily accessible. By examining health systems internationally (although the editor acknowledges by no means comprehensively) a clear picture emerges of the disparate but also common difficulties in creating systems for fair allocation of resources. Justification for the belief in the necessity for philosophical analysis as a base for health policy and reform is well illustrated. As David Seedhouse points out, some of the chapters illustrate very clearly the fact that philosophy and practice can seem worlds apart when it comes to health policies. Yet, he asks, how can a health reformer make cogent changes unless thought has been given to the principles which should guide the practical reform process? Arguments against apartheid for example, must rest on an alternative theory of social justice, and the Oregon experiment is based on the principle that human beings are of equal value.

This book will be of particular value to anybody involved in forming health policy, health care research or health ethics. However, it would also be of interest to any health professional or student interested in exploring the philosophical basis of practical health care.

MARGARET REDDOCH Imperial College Health Service, London SW7

\section{Philosophy, Psychology and Psychiatry}

\section{Edited by A Phillips Griffiths \\ Cambridge, Cambridge University \\ Press, 1994, 243 pages, $£ 13.95$.}

These indeed are exciting times for philosophy and psychiatry, as Fulford remarks in his interesting essay on mind and madness which begins this book. A newly emerging mutual interest, sketched by Fulford, directs philosophers towards psychiatric concepts, categories and practices, and psychiatrists toward the theory, values, metaphysics, epistemology and methodology informing their profession.

The interest of the philosophers is, on reflection, understandable. Anthony Quinton has observed that given their status as experts on rationality - and we might add, on the moral concepts of personal autonomy, and responsibility - the puzzle lies with philosophers who aren't curious about psychopathology, not with those who are (page 5). And the interest of philosophers has been piqued. Several topics with clear relevance for medical, and particularly, psychiatric, ethics, such as personal identity, have recently received the attention of a significant number of philosophers and benefited from philosophical analysis and scholarly 